\title{
Reaction of Iodine into Poly(vinyl acetate) Particles Suspended in Aqueous Solution in the Presence of Potassium Iodide
}

\author{
Sadao Hayashi, Ichiro Kaneko, and Nobumasa Hojo \\ Faculty of Textile Science and Technology, Shinshu University, \\ Ueda, Japan.
}

(Received June 8, 1973)

\begin{abstract}
Iodine transfers into solid poly(vinyl acetate) (PVAc) in aqueous solution in the presence of potassium iodide, and forms the red-violet complex with PVAc. The reaction amount of iodine transfered into the PVAc particles, which were prepared by the suspension polymerization of vinyl acetate, was measured by a stopped-flow apparatus. The initial reaction amount transfered was proportional to the square root of the reaction time and to the concentrations of PVAc and iodine, and was in inverse proportion to the particle radius of PVAc. These results were in agreement with the theoretical equation derived by assuming that the transfer of iodine into the PVAc particles obeys Fick's law. It was concluded that the initial reaction rate of iodine trasfer into the PVAc particles is controlled by diffusion of iodine into the particles.

KEY WORDS Iodine / Potassium Iodide / Poly(vinyl acetate) / RedViolet Complex / Stopped-Flow Method / Extinction / Diffusion /
\end{abstract}

Although it has been known that PVAc forms a red-violet complex with iodine in aqueous solution in the presence of potassium iodide, ${ }^{1-5}$ little attention has been paid to the mechanism of the complex formation. We have already found that when a methanolic solution of PVAc and iodine is added to an aqueous solution of potassium iodide, the red-violet complex is formed in the aquaous solution as an apparent homogeneous system, just as partially saponified water-soluble PVAc does. ${ }^{6}$ The complex formation between partially saponified PVAc and iodine is based on the block distribution of the acetic ester groups in the polymer chain. ${ }^{5}$ Furthermore, the potentiometric titration of PVAc with iodine has been investigated; here it was observed that if the reaction system is heterogeneous, the same titration curve as that of amylose is obtained, but if it is homogeneous, the titration curve is similar in shape to those of amylopectine and partially saponified PVAc. ${ }^{7,8}$ These facts suggest that in a heterogeneous system iodine reacts into PVAc in solid form. This paper will report in some detail on the reaction of iodine into the PVAc particles prepared by the suspension polymerization of vinyl acetate.

\section{EXPERIMENTAL}

\section{Preparation of PVAc Suspension}

The PVAc suspensions were prepared by the suspension polymerization of vinyl acetate using potassium persulfate as initiator; the suspensions were then dialyzed for one week to remove any excess initiator and unreacted monomer. The degree of polymerization of PVAc which was obtained by air-drying the PVAc suspension on a polyethylene film was measured in a Ubbelohde viscometer at $30^{\circ} \mathrm{C}$ in acetone, and was calculated using an equation proposed by Nakajima. ${ }^{9}$ Control of the polymer particle size was carried out by varying the monomer concentration in the polymerization system, following Okamura, et $a l .{ }^{10}$ The particle size of PVAc suspended in water was determined from turbidity data by using a Hitachi 139 spectrophotometer according to the procedure of Loebel. ${ }^{11}$ The recipes of polymerization and the properties of the PVAc suspensions obtained are indicated in Table I.

\section{Measurement of Reaction Amount of Iodine Transfered into PVAc Particles}

Since the red-violet complex between PVAc and iodine in aqueous solution in the presence 


\section{S. Hayashi, I. Kaneko, and N. Hojo}

Table I. Recipes of polymerization and properties of PVAc suspension ${ }^{\mathrm{a}}$

\begin{tabular}{ccccccc}
\hline $\begin{array}{c}\text { Exptl } \\
\text { No. }\end{array}$ & $\begin{array}{c}\text { Monomer } \\
\text { concn, } \\
\%\end{array}$ & $\begin{array}{c}\text { Initiator } \\
\text { concn, } \\
\%\end{array}$ & $\begin{array}{c}\text { Conversion, } \\
\%\end{array}$ & $\begin{array}{c}\text { Degree of } \\
\text { polymerization } \\
\text { of PVAc }\end{array}$ & $\begin{array}{c}\text { Average par- } \\
\text { ticle radius, } \\
\AA\end{array}$ & $\begin{array}{c}\text { Value of } \\
t^{1 / 2} / E_{t} \text { b } \\
\text { sec }^{1 / 2}\end{array}$ \\
\hline 1 & 0.50 & 0.10 & 97.2 & $-c$ & 330 & 6.7 \\
2 & 1.00 & 0.10 & 95.3 & 2190 & 580 & 8.3 \\
3 & 5.00 & 0.10 & 91.3 & 3160 & 1550 & 23.9 \\
4 & 5.00 & 0.05 & 88.2 & 4550 & 1500 & 26.7 \\
5 & 10.00 & 0.10 & 93.0 & 3630 & 2500 & 38.2 \\
6 & 15.00 & 0.10 & 93.2 & 3980 & 2850 & 48.5 \\
\hline
\end{tabular}

a Polymerization temperature, $70^{\circ} \mathrm{C}$; polymerization time, $1.5 \mathrm{hrs}$.

b $t^{1 / 2} / E_{\mathrm{t}}$ was calculated from the result at a reaction time of $1 \mathrm{sec}$ in Figure 2 .

c Degree of polymerization was not measured because of the small amount of PVAc.

of potassium iodide has an absorption maximum at $5100 \AA$ wavelength, the reaction amount of iodine transfered into the PVAc particles was determined from the increase in the extinction at the wavelength of the absorption maximum. The extinction was measured in a Union Giken stopped-flow apparatus. The temperature was maintained at $15^{\circ} \mathrm{C}$. Equal volumes of PVAc suspension and iodine-potassium iodide solution were mixed in the apparatus, where a cell with an optical path of $10 \mathrm{~mm}$ was used. The light transmittance change with time was recorded on a National oscilloscope screen (type VP-526A), and a photograph was taken. At the same time, the change was recorded on a Hitachi recorder (type QPD-54), and the extinction was computed using the results from both oscilloscope and recorder.

\section{IR Spectra of PVAc-Iodine Complex}

A thin film of PVAc was prepared by casting a methanolic solution of PVAc on a polyethylene film, and then dried under reduced pressure. The PVAc film was dipped in an aqueous solution of iodine and potassium iodide, excess water on the film was soaked up with filter paper, and then the IR spectra of the film were measured by a Nippon Bunko IR spectrophotometer (IR-E).

\section{RESULTS}

\section{Effect of Particle Size}

An example of the oscillogram of the color reaction between PVAc suspended in aqueous solution and iodine obtained by the stopped-flow method is shown in Figure 1. The light transmittance decreased rapidly with time. Figure 2 indicates the plots of the extinction $\left(E_{\mathrm{t}}\right)$ against the square root of the reaction time $\left(t^{1 / 2}\right)$. The concentrations of PVAc, iodine, and potassium iodide were kept at $0.100 \mathrm{~g} / l, 2.22 \times 10^{-4} \mathrm{~mol} / l$, and $5.10 \times 10^{-3} \mathrm{~mol} / l$, respectively. The increase in $E_{\mathrm{t}}$ was influenced considerably by the particle size of PVAc. This fact suggests a dependence on the particle surface of PVAc through which the iodine reacts. It can be seen from Figure 2 that the plots for each particle size indicate a good linear relationship between $E_{\mathrm{t}}$ and $t^{1 / 2}$. Reasoning from the result that $E_{\mathrm{t}}$ increases with decrease in the particle size, we decided to plot

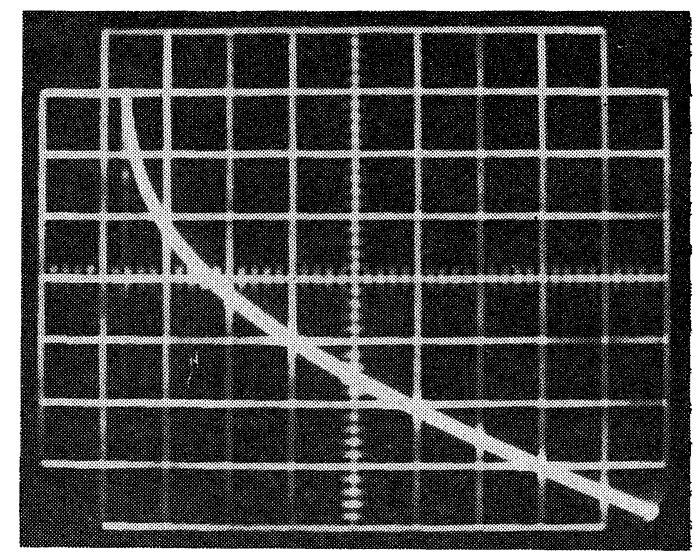

Figure 1. Oscillogram of reaction between PVAc suspended in aqueous solution and iodine in the presence of potassium iodide by stopped-flow method. Horizontal scale is 1 sec per major division. Vertical axis represents transmittance at 5100-A wavelength. 
Reaction of Iodine into Poly(vinyl acetate) Particles Suspended in Aqueous Solution

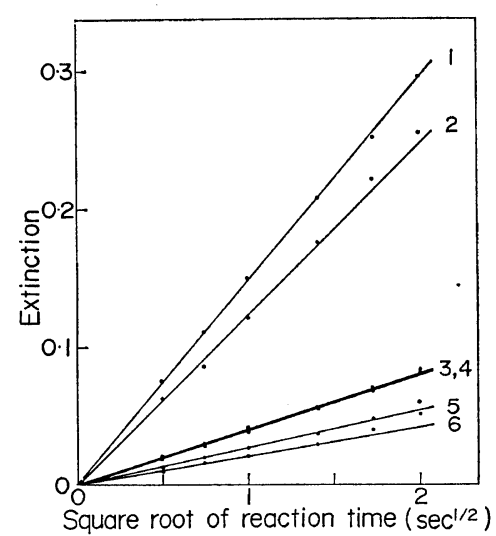

Figure 2. Relationships between square root of reaction time and extinction for various particle sizes. Particle radius, ̊: 1,$330 ; 2,580 ; 3,1550$; 4,$1500 ; 5,2500 ; 6,2850$.

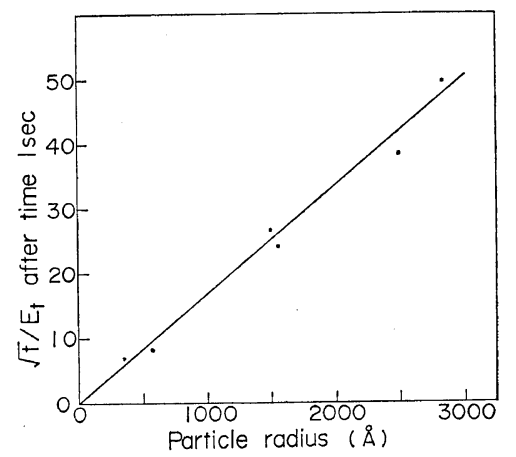

Figure 3. Effect of particle size on $t^{1 / 2} / E_{\mathrm{t}}$ after $1 \mathrm{sec}$.

$t^{1 / 2} / E_{\mathrm{t}}$ against the particle radius of PVAc. The values of $t^{1 / 2} / E_{\mathrm{t}}$ which were estimated at the reaction time of $1 \mathrm{sec}$ are listed in Table $I$, together with the properties of the PVAc suspension. The relationship between the particle radius of PVAc and $t^{1 / 2} / E_{\mathrm{t}}$ is shown in Figure 3 , from which it is found that $t^{1 / 2} / E_{\mathrm{t}}$ is proportional to the particle radius of PVAc.

In addition, the two samples (Exptl No. 3 and 4 in Table I) which are almost the same in particle size but have a large difference in the degree of polymerization of PVAc were compared in order to examine the effect of the degree of polymerization on $E_{\mathrm{t}}$. As Figure 2 shows, the reaction amount of iodine transfered into the PVAc particles was independent of the degree of polymerization of PVAc.

\section{Effect of PVAc Concentration}

Experiments were carried out by varying the PVAc concentration from $0.050 \mathrm{~g} / l$ to $0.350 \mathrm{~g} / l$, where the iodine and potassium iodide concentrations were held at $2.22 \times 10^{-4} \mathrm{~mol} / l$ and $5.10 \times 10^{-3} \mathrm{~mol} / l$, respectively. The PVAc suspensions of Exptl No. 1 and 3 in Table I were used as samples.

$E_{\mathrm{t}}$ for the two PVAc suspensions was linearly correlated with $t^{1 / 2}$ in every case. Figure 4 represents the effects of the PVAc concentration on $E_{\mathrm{t}}$. The relationships between $E_{\mathrm{t}}$ and the PVAc concentration were linear for each particle size.

\section{Effect of Iodine Concentration}

The sample used in this experiment was the PVAc suspension of Exptl No. 1 in Table I. The PVAc concentration was kept at $0.100 \mathrm{~g} / l$. $E_{\mathrm{t}}$ was measured by varying the iodine concentration from $0.50 \times 10^{-4} \mathrm{~mol} / l$ to $3.50 \times 10^{-4} \mathrm{~mol} / l$ at a fixed concentration of potassium iodide $\left(5.28 \times 10^{-3} \mathrm{~mol} / l\right)$.

The $t^{1 / 2}-E_{\mathrm{t}}$ curves are graphed in Figure 5 . As is shown in Figure 5, although in the initial period of reaction linear relationships were obtained for each iodine concentration, at a high concentration of iodine the deviation from a straight line increased with the passage of time. From the fact that a PVAc film which has formed a complex with iodine is swelled by water to several times the size of the original film, ${ }^{8}$ this behavior may be explained by the acceleration of the complex formation based on swelling of the particle in a high concentration

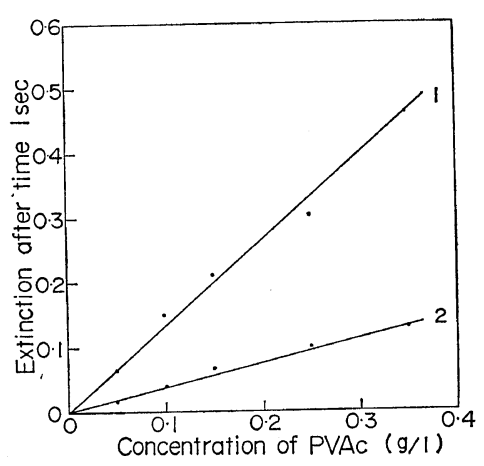

Figure 4. Effect of PVAc concentration on extinction after $1 \mathrm{sec}$. Particle radius: 1, $330 \AA$ A; 2, $1550 \AA$ A. 


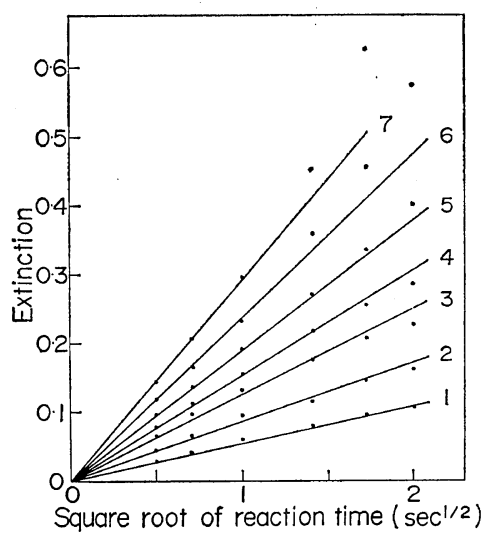

Figure 5. Relationships between square root of reaction time and extinction for particles having $330-\AA$ radius. Iodine concentration, $10^{-4} \mathrm{~mol} / \mathrm{l}$ : $1,0.50 ; 2,1.00 ; 3,1.50 ; 4,2.00 ; 5,2.50 ; 6,3.00$; $7,3.50$.

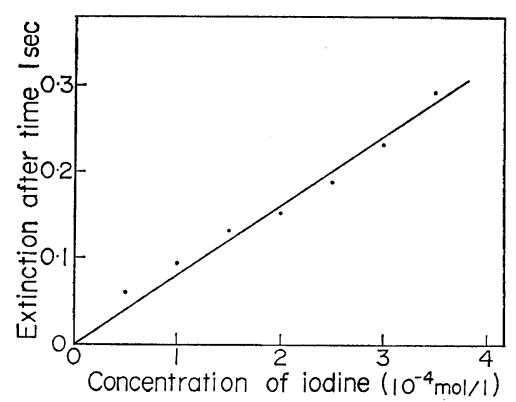

Figure 6. Effect of iodine concentration on extinction after $1 \mathrm{sec}$.

of iodine. In Figure 6, the effect of the iodine concentration of $E_{\mathrm{t}}$ in the initial period of reaction is indicated. As can be seen in Figure 6, the plots of $E_{\mathrm{t}}$ against the iodine concentration gave almost a straight line.

Accordingly, the $E_{\mathrm{t}}$ change in the reaction amount of iodine transfered into the PVAc particles can be summarized by the following experimental equation:

$$
E_{\mathrm{t}}=K\left[[\mathrm{PVAc}]\left[\mathrm{I}_{2}\right] / r\right] t^{1 / 2}
$$

where $K$ is a constant, [PVAc] is the concentration $(\mathrm{g} / \mathrm{l})$ of PVAc, $\left[\mathrm{I}_{2}\right]$ is the concentration $(\mathrm{mol} / \mathrm{l})$ of iodine, and $r$ is the particle radius of PVAc.

\section{DISCUSSION}

General Characteristics of PVAc-Iodine Complex

The formation of the PVAc-iodine complex does not take place in the absence of potassium iodine or in organic solvents. When a methanolic solution of PVAc and iodine is added to an aqueous solution of potassium iodide, the red-violet complex characterized by $\lambda_{\max }=$ $5100 \AA$ is formed.

The degree of red-violet color for partially saponified PVAc is known to depend very much on the distribution of the acetic ester group in the polymer. ${ }^{7}$ Although the red-violet complex is associated with the acetic ester group in the polymer, if the acetic ester groups are distributed at random in the polymer chain, the complex is not formed. This fact suggests that the mechanism of the complex formation between partially saponified PVAc and iodine is essentially the same as that between PVAc and iodine.

IR spectra of the PVAc-iodine complex in film are shown in Figure 7, where it is observed that the band at $1748 \mathrm{~cm}^{-1}$ assigned to the $\mathrm{C}=\mathrm{O}$ streching vibration shifts to $1730 \mathrm{~cm}^{-1}$ and that the band at $1233 \mathrm{~cm}^{-1}$ assigned to the $\mathrm{C}-\mathrm{O}$ streching vibration shifts to $1265 \mathrm{~cm}^{-1}$. These changes indicate that the formation of the PVAc-iodine complex is due to the bonding between iodine and the unshared electrons of the oxygen atom of the $\mathrm{C}=\mathrm{O}$ group in the

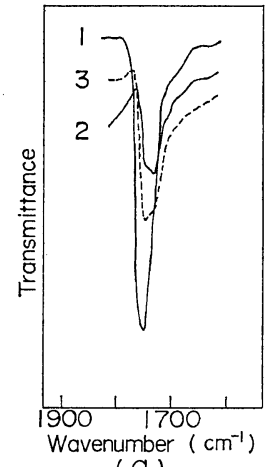

( a )

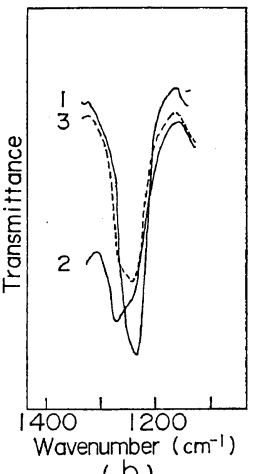

(b)
Figure 7. IR spectra of PVAc and PVAc-iodine complex in film. (a) $\mathrm{C}=\mathrm{O}$ streching vibration, (b) $\mathrm{C}-\mathrm{O}$ streching vibration: 1, PVAc; 2 , PVAciodine complex immediately after reaction (redviolet color); 3 , after 5 min of reaction (brown color). 
PVAc molecule, since the shifts are similar to those observed for the ester-iodine complex. ${ }^{12}$

From the linearity of the Benesi-Hildebrand plot $^{13}$ for the system in which the concentration of partially saponified PVAc exists sufficiently in excess as compared with that of iodine, it is presumed that the red-violet complex is also a single $1: 1$ type. The equilibrium constant was found to be order $10^{5}$ at $15^{\circ} \mathrm{C}$. $^{14}$

Kinetics of Reaction of Iodine Transfer into PVAc Particles

For an initial period of reaction, since only the outer spherical shell of the PVAc particle reacts with the iodine, this shell is approximated by a slab of the PVAc particle. Accordingly, the $E_{\mathrm{t}}$ change in the reaction between PVAc and iodine will be given as follows:

$$
E_{\mathrm{t}}=\varepsilon \cdot S \cdot N \cdot Q \cdot L
$$

where $\varepsilon$ denotes the molecular extinction coefficient of the complex; $S$, the surface area of a particle; $N$, the particle number; $Q$, the amount of the complex formed through a unit area of the PVAc particles; and $L$, the thickness of the cell.

We assume that the transfer of iodine into the PVAc particles obeys Fick's law as given below, provided that the diffusion coefficient (D) is constant.

$$
\frac{\partial C}{\partial t}=D \frac{\partial^{2} C}{\partial X^{2}}
$$

where $C$ is the concentration of the diffusing substance, $t$ is the time from the beginning of diffusion, and $X$ is the distance from the surface.

If an equation for diffusion into a semiinfinite solid is assumed, the total amount $\left(A_{\mathrm{t}}\right)$ of substance diffused through a unit surface area will be given by the following equation. ${ }^{15}$

$$
A_{\mathrm{t}}=\left(2 C_{0} / \pi^{1 / 2}\right)(D \cdot t)^{1 / 2}
$$

where $C_{0}$ is the concentration of the diffusing substance on the surface.

Since it is thought that the amount of complex formation is proportional to the total amount of iodine diffused, eq 2 is written as

$$
E_{\mathrm{t}}=K_{1}\left[[\mathrm{PVAc}] C_{0} / r\right] t^{1 / 2}
$$

where $K_{1}=6 K_{2} \cdot \varepsilon \cdot L \cdot D^{1 / 2} / \rho \cdot \pi^{1 / 2},\left(K_{2}\right.$ is taken as constant from $Q=K_{2} \cdot A_{\mathrm{t}}$, and $\rho$ is the density of PVAc.).

If $C_{0}$ is proportional to the concentration of the diffusing substance in solution in the same way as for diffusion of dyes into fibers, ${ }^{16} E_{\mathrm{t}}$ can be approximately represented by

$$
E_{\mathrm{t}}=K_{3}\left[[\mathrm{PVAc}]\left[\mathrm{I}_{2}\right] / r\right] t^{1 / 2}
$$

where $K_{3}=6 K_{2} \cdot K_{4} \cdot \varepsilon \cdot L \cdot D^{1 / 2} / \rho \cdot \pi^{1 / 2},\left(K_{4}\right.$ is taken as constant from $\left.C_{0}=K_{4} \cdot\left[\mathrm{I}_{2}\right]\right)$.

This theoretical eq 6 is in close agreement with the experimental eq 1 . Therefore, it may be concluded that the initial reaction rate of iodine into the PVAc particles is controlled by diffusion of iodine into the particles.

If the extinction at equilibrium in the reaction is indicated as $E_{\infty}, E_{\infty}$ is represented as $K_{2} \cdot \varepsilon \cdot(4 / 3) \pi \cdot r^{3} \cdot N \cdot C_{0} \cdot L$. Consequently, the conversion $\left(E_{\mathrm{t}} / E_{\infty}\right)$ is given by

$$
E_{\mathrm{t}} / E_{\infty}=(6 / r)(D \cdot t / \pi)^{1 / 2} .
$$

Equation 7 agrees with the diffusion equation proposed by Boyd, et al., ${ }^{17}$ where the diffusion of ions into the ion-exchange resins was investigated.

Because $E_{\infty}$ was unknown, we could not determine an accurate value of $D$ from eq 7 . However, since $D$ is proportional to the square of the radius, as described in eq 7 , it would be expected that $D$ is very small.

\section{Activation Energy of Diffusion}

The activation energy of diffusion $\left(E_{\mathrm{d}}\right)$ is given by the following equation.

$$
D_{\mathrm{t}}=D_{0} \exp \left(-E_{\mathrm{d}} / R T\right)
$$

where $D_{\mathrm{t}}$ is the diffusion coefficient at $t^{\circ} \mathrm{C}, D_{0}$ is a constant, $R$ is the gas constant, and $T$ is the absolute temperature.

From eq 7 , since $\log D_{\mathrm{t}}$ is proportional to $\log E_{\mathrm{t}}$, we determined $E_{\mathrm{d}}$ by using $E_{\mathrm{t}}$. The $\log E_{\mathrm{t}}-1 / T$ plot is shown in Figure 8. From the slope of the straight line, $E_{\mathrm{d}}$ was found to be $26.5 \mathrm{kcal} / \mathrm{mol}$ in the temperature region below $18^{\circ} \mathrm{C}$. On the basis of the glass-transition temperature of PVAc, this result may be explained by the mobility of the polymer. On the other hand, in the temperature region above $18^{\circ} \mathrm{C}$, an abnormal result was obtained. Since the concert effect of the ester groups in PVAc and the fixed zig-zag form of the $\mathrm{C}-\mathrm{C}$ bond which appears to be one of the requisites for the formation of the PVAc-iodine complex 


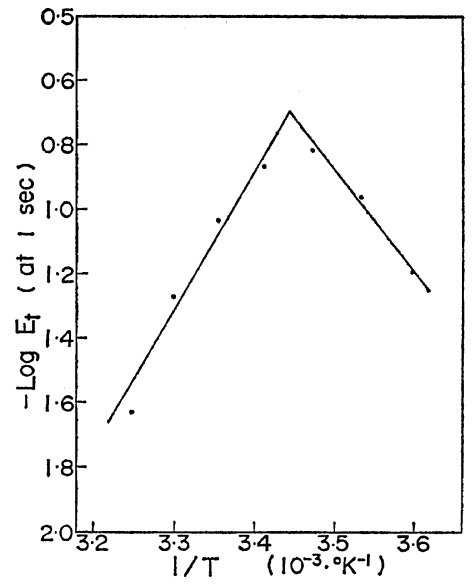

Figure 8. Relationship between $\log E_{\mathrm{t}}$ and $1 / T$ : Sample, Exptl No. 1 in Table I; PVAc concentration, $0.100 \mathrm{~g} / l$; iodine concentration, $2.30 \times 10^{-4} \mathrm{~mol} / l ;$ potassium iodide concentration, $5.28 \times 10^{-3} \mathrm{~mol} / \mathrm{l}$.

decrease as the molecular motion of PVAc increases, this abnormal behavior for $E_{\mathrm{d}}$ can be satisfactorily explained by a decrease in the number of reaction sites in PVAc at elevated temperatures. This will be supported also by the temperature dependence of the color reaction between the PVAc copolymers having various glass-transition temperatures and iodine, as indicated in a previous paper. ${ }^{6}$

H. J. van der Hul, et al., have already pointed out that the polymer particles prepared by suspension polymerization are hydrated by the sulfate end groups of the polymer molecules coming from the initiator. ${ }^{18}$ The glass-transition temperature of the hydrated polymer is expected to be lower than that of the unhydrated polymer, because the hydrated water affects as a plasticizer. This appears to be the reason why the $E_{\mathrm{t}}$ maximum in Figure 8 was found in the vicinity of $18^{\circ} \mathrm{C}$ below the glass-transition temperature of PVAc.

\section{REFERENCES}

1. J. H. Graff, Paper Trade J., 41, 31 (1946).

2. H. Schweepe, Paint Technology, 27, 14 (1963).

3. F. D. Hartley, J. Polym. Sci., 34, 397 (1959).

4. R. Patsiga, M. Litt, and V. Stannett, J. Phys. Chem., 64, 801 (1960).

5. S. Hayashi, C. Nakano, and T. Motoyama, Kobunshi Kagaku (Chem. High Polymers), 20, 303 (1963).

6. S. Hayashi, C. Kawamura, and M. Takayama, Bull. Chem. Soc. Japan, 43, 537 (1970).

7. S. Hayashi, T. Nakabayashi, and K. Yoshida, ibid., 43, 3292 (1970).

8. S. Hayashi, M. Kishibe, and N. Hojo, ibid., 46, 318 (1973).

9. A. Nakajima, Kobunshi Kagaku (Chem. High Polymers), 6, 451 (1948).

10. S. Okamura and J. Tanaka, ibid., 5, 266 (1948).

11. A. B. Loebel, Ind. Eng. Chem., 51, 118 (1959).

12. H. Yamada and K. Kozima, J. Amer. Chem. Soc., 82, 1544 (1960).

13. H. A. Benesi and J. H. Hildebrand, ibid., 71, 2703 (1949).

14. Our unpublished data.

15. R. Higbie, Trans. Amer. Inst. Chem. Eng., 31, 365 (1935).

16. M. Sekido and K. Matzui, Seni Gakkaishi, 20, 783 (1964).

17. G. E. Boyd, A. W. Abamson, and L. S. Myers, J. Amer. Chem. Soc., 69, 2836 (1947).

18. H. J. van der Hul and J. W. Vanderhoff, Brit. Polym. J., 2, 121 (1970). 